\title{
Multi-Featured Android Car
}

\author{
Namrata Mahakalkar Khade ${ }^{1}$, Rakhi Kumari ${ }^{2}$, Tushar Wahane ${ }^{3}$, Aditi Gudadhe ${ }^{4}$, \\ Dnyaneshwar Nagrikar ${ }^{5}$ \\ Professor and Head of Dept. Computer Science and Engineering, \\ Priyadarshini Institute of Engineering and Technology, Nagpur, India ${ }^{1}$ \\ UG Students, Computer Science and Engineering, \\ Priyadarshini Institute of Engineering and Technology, Nagpur, India ${ }^{2,3,4,5}$
}

\begin{abstract}
Our paper provides design and implementation of prototype car that is controlled through Smartphone. In this Project mobile phone is used for controlling a prototype car. Android application provides graphical interface to the user. The prototype car consist of two DC motor with motor driver, Bluetooth module, Arduino microcontroller, some wires, wifi camera, led lights, batteries etc. Two motors are used for controlling speed and direction of car and one motor is just a general purpose. Bluetooth module receives signals from android application and sends data to the Arduino microcontroller unit. This Arduino unit operates the received data and sends control signal to DC motor. Android studio software is used for Arduino programming and android application is downloaded from play store. We will use another android phone for wifi camera.
\end{abstract}

Keywords: Android Remote control, Advanced Driving version for Car through Android phone with live video streaming

\section{INTRODUCTION}

This is the age of Smartphone's where the world uses Smartphone's in our day to day life, and people want everything to be controlled through their Smartphone's.

- So the purpose of this project is to develop such a user interface to control a car through a wireless technology. We create an interface between the car and Smartphone so that the data should be passed in both the direction.

- In this project we are using Bluetooth for controlling a car which also provides live video streaming. We are able to achieve this as we have developed a prototype for this module.

- Our prototype module runs well and can be controlled by two modes.

- One, from any Bluetooth/wifi activated computers.

- Second, from an android phone by touching buttons on the mobile application.

- An android controlled car is built using Arduino Uno Microcontroller in which communication is done through Bluetooth and camera uses wifi technology for video streaming.

\section{PROPOSED SYSTEM}

The proposed system consists of two main units:

1. Arduino Uno microcontroller.

2. Android phone.

3. Bluetooth Application

4. Bluetooth module HC-05

5. Wifi camera module

1. Arduino Uno: The proposed device uses Arduino Uno microcontroller .It is an open source microcontroller board which has 14 digital pins and 6 analog pins which may be interfaced to various expansion boards and other circuits. It require $9 \mathrm{v}$ power supply . 
Vol. 7, Issue 8, August 2018

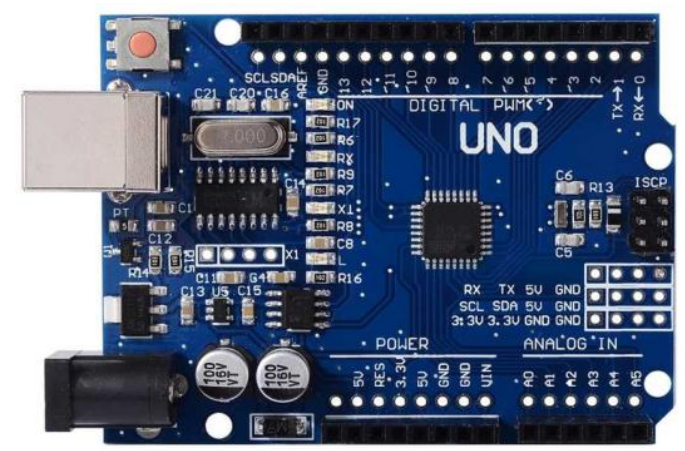

II. HC-05 Bluetooth module: The HC-05 module is a MASTER/SLAVE module. By default the factory setting of HC-05 is SLAVE. The Role of the module (Master or Slave) can be configured only by AT COMMANDS. The slave cannot begin a connection with another Bluetooth device, but can accept connections. Master module can begin a connection with other devices. The user can use it simply for a serial port replacement to initiate a connection between microcontroller and GPS, Computer to your embedded project, etc.

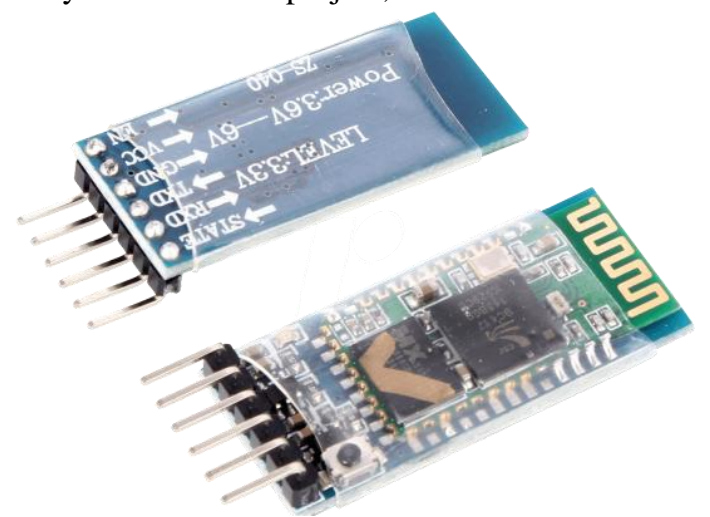

III. L293D Motor Driver: The motor driver is a driver module for DC motors that allows us to control the speed and direction of two motors at the same time. This Motor Driver is designed and developed by considering L293D IC. L293D is a 16 Pin Motor Driver IC. This is designed to provide bidirectional drive currents at voltages from $5 \mathrm{~V}$ to 36 V.

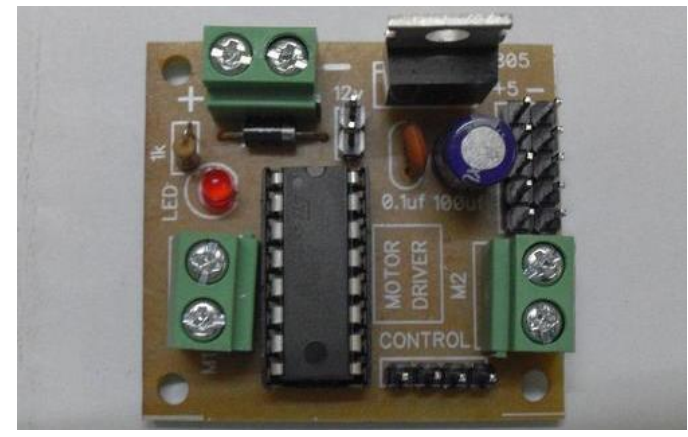

IV. Jumper Wires: Jumper wire is an electrical wire that has a connector or pin at the end side of it that is normally used for interconnecting the components of breadboard without using the solder machine. It may be male to male or male to female.

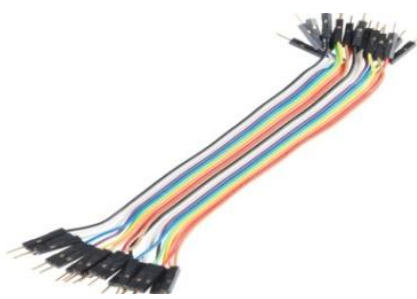




\section{Wifi Camera}

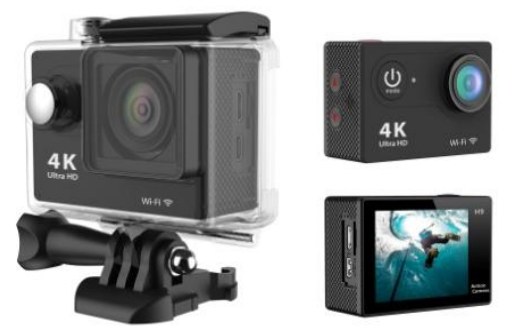

The camera will record your video at 15 frames per second and capture images at 16 megapixels and sends it instantly to your wifi enabled device i.e mobile or computer. The $2.4 \mathrm{GHz}$ Cameras wifi range is 30 meters.

\section{Pan and Tilt Servo}

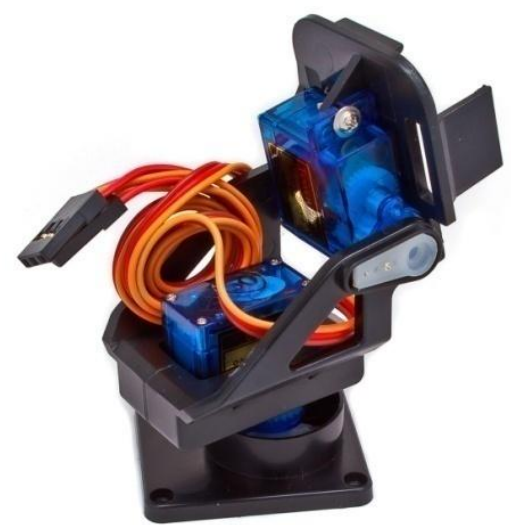

The pan and tilt servo rotates $180^{\circ}$ from side to side and can tilt up and downward around $150^{\circ}$. This motor is a plain everyday analog servos we can use microcontroller or driver. The motor helps in fixing the camera when rotating and tilting it up and down.

\section{RESEARCH METHODOLOGY}

Wiring connection with Arduino

1. Module 5V i.e. VCC is connected to Arduino's 5V.

2. Module GND is connected to Arduino's GND.

3. Module 1 is connected to Arduino's D8.

4. Module 2 is connected to Arduino's D9.

5. Module 3 is connected to Arduino's D10.

6. Module 4 is connected to Arduino's D11.

7. Module Motor terminals is connected to DC motors.

8. Module VSS power terminal is connected to External power source of $9 \mathrm{~V}$.

9.Pan and tilt is Connected to GND and Vin.

10.Led is connected to one GND pin and one to Battery

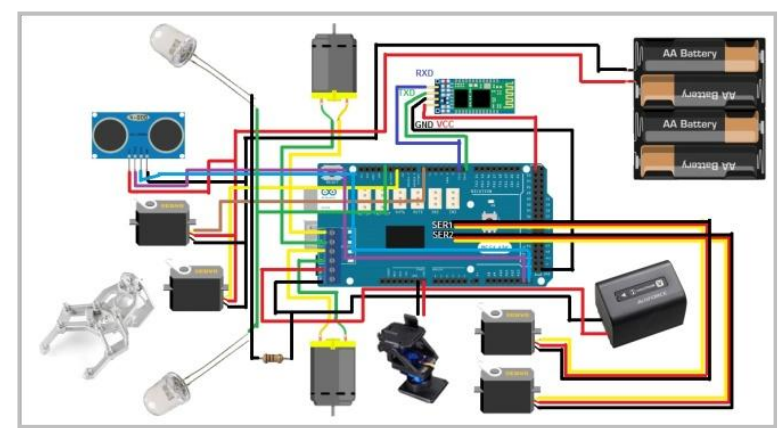




\section{Requirement Analysis}

$\begin{array}{ll}\text { - } & \text { Hardware } \\ \text { - } & \text { Arduino uno } \\ \text { - } & \text { L293D motor driver } \\ \text { - } & \text { Bluetooth Module HC-05 } \\ \text { - } & \text { Jumper wires } \\ \text { - } & \text { Power Supply 9v (x2) } \\ \text { - } & \text { Android phone (x2) } \\ \text { - } & \text { 3 or 4 Wheel Chassis } \\ \text { - } & \text { DC motors } \\ \text { - } & \text { Wifi camera or Arduino camera } \\ \text { - } & \text { Servo pan and tilt servo } \\ \text { - } & \text { Led lights (optional) }\end{array}$

\section{Development Tool}

- $\quad$ Arduino Studio

- $\quad$ Bluetooth RC Application

- $\quad$ Android application kurebas v2.0

- $\quad$ 51duino Computer application

\section{FUTURE SCOPE}

This project is an updated version of Bluetooth controlled car and can be further developed by adding new features to it such as voice reorganization and various sensors such as gas sensor, obstacle sensor, ultrasonic sensor etc. This is a two way interface project as sharing and receiving of data is done from both end that is phone as well as from car. This can also be used in military forces for spying or checking the situations where humans cannot physically be present.

\section{CONCLUSION}

The aim of this paper is to accomplish the smart living, for example the home lighting control system using Bluetooth Technology. Smartphone and robotics if paired together and wifi camera sends live video streaming to either mobile phone or computer application. Mobile phones can also be used for creating new features such as reorganization of voice. Smartphone containing Bluetooth and Bluetooth receiver HC-05 and creation interface between them through arduino can simplify our lifestyle and this will automatically help the senior citizens and physically challenged people also.

\section{REFERENCES}

[1]. http://www.ardumotive.com/blog/arduino-wifi-robot-with-camera

[2]. http://www.ardumotive.com/bluetooth-rc-car.html

[3]. https://www.youtube.com/watch?v=ZSPtBw6gUEU

[4]. http://robokits.co.in

[5]. www.Robohub.com

\section{BIOGRAPHY}

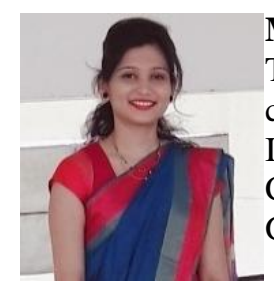

Mrs. Namrata S. Khade is working as a Asst. Professor at Priyadarshini Institute of Engineering and Technology. She is having 8 years of experience in the field of teaching to engineering students. She completed her Engineering in 2007 and Master in Engineering in 2013. She is a member of IEEE, ISTE and CSI. She is having more than 20 research published in International Journals and Conferences. Her interests include distributed parallel computation, System Programming, Computer Graphics and Wireless Sensor Network. 